\title{
High Speed Trains: A Review
}

\author{
M. Ahmed Ali Baig ${ }^{1}$, S. A. Khan ${ }^{2}$, M. Ansar Ali Baig ${ }^{3}$ \\ ${ }^{I}$ Department of Mechanical Engineering, CMR Technical Campus, JNTUH, India \\ ${ }^{2}$ Department of Mechanical Engineering, Faculty of Engineering, IIUM, Malaysia \\ ${ }^{3}$ Department of Electronics \& Communication Engineering, CMR Technical Campus, JNTUH, India
}

\begin{abstract}
This review introduces the concept of high-speed trains in simplistic engineering terms. This review aims to discuss how the high speed trains function and what implications they have on public transportation. The objective of this review is to introduce to the reader the functions of a high-speed train. The scope of this review only extends to reviewing the relevant material provided. This review does not involve an experimental or simulation study. The paper is organized into four sections. Types of tracks, Power, Flow field around the train and economic efficiency of the train. In the depth of this article, the detailed explanation of the track system, power generation, aerodynamics, and the economic efficiency of the high speed train are provided, which will give a perfect visualization of the mechanism [how it works] of the whole system.
\end{abstract}

Keywords: Aerodynamic drag, Derailment, Maglev, Speed, traction.

\section{Introduction}

"High speed train", by hearing this phase most of the people obtain a visualization of a train which is moving at a tremendous speed (e.g. Japanese Bullet Train, fastest train alive in the world). But is the concept of high speed train really simple? Is it just moving at a great speed because it is obvious? The answer is "no".

As intellects say, "don't judge a book by its cover", the straight path looking concept of high speed train is a complex maze in reality. To grasp the concept of it [high speed rail], individuals need to be fully aware and properly understand every particular detail [working process, parts to be mainly focused on] of it. But before obtaining a vivid explanation of the concept, gaining a proper definition of high speed train will be more understandable.

High speed train is a kind of train which uses a sophisticated rolling stock system [a system whereby vehicles move on a railway, special designed train sets] and a specialized track to sustain a very high speed. High speed train doesn't have a worldwide standard over its speed. But in existing system and lines a high speed train can obtain speeds up to 200 or $220 \mathrm{~km} / \mathrm{h}$ (newly proposed line can elevate it up to $250 \mathrm{~km} / \mathrm{h}$ ). [10]

Keywords such as induction, derailment aerodynamic drag etc. are very simplistic engineering terms and do not require detailed explanation. A person with non-engineering background and knowledge can still find the article useful as the keywords used in this report cater to all. It is believed that high speed train is an important transport in this modern world and will play a very important role [in terms of speed and traveling] in near future. Ergo, to introduce it to the people and propose some valuable ideas toward its development is the main goal/objective of this article.

\section{Types Of Tracks}

High speed trains require different types of tracks to run, as the wear on the track from high velocity trains affect it greatly. Hence there are many different forms of railway meant to be able to handle the stress from the passing trains as well as to avoid accidents from occurring and making sure that the passengers are safe.

\subsection{Maglev}

Maglev system were first made and used in Japan Maglev tracks work on a system of magnetic levitation to move the trains without having contact with the actual train. The magnets allow for the train to move by propulsion allowing for the train to be able to travel at exceedingly fast speeds. Guang Yang \& Zhenmin Tang explain this concept as "The maglev train is levitated by the attraction between the controllable suspension electromagnet and the stator pack, and' the suspension interstice is hold steadily by controlling suspending exciting current" [1]. This theory can be seen in magnets whereas opposite poles attract, but when similar poles are brought close together, there is a magnetic pull. The repulsion allows the train to levitate. As previously mentioned, by exciting the current, the constant shift in polarity allows for the magnetic field to pull the train and this causes thrust for the train to move forward. With the lack of friction due to not having any 
contact with the floor, this allows for high speeds to be achieved [2]. This technology has permitted for trains in Japan to exceed a speed of $600 \mathrm{~km} / \mathrm{h}$. [3]

\subsection{Rail and Wheel}

The Rail and wheel is a system where as a flanged wheel is attached to the axle underneath the train. This system has been in use for a long time, however the first high speed rail and wheel system was invented in 1960 [1]. The wheel must be designed such as to have proper interaction with the rail or else this would cause complications and inefficiency.

With the invention of high speed trains, comes the discussion of safety in utilizing these trains. A major common incident is derailment of the train. Derailment could happen for many multiple reasons.

Such as:

- Broken rails

- Broken wheels

- Improper interaction between rail and wheels

- High speed banking

For high speed trains, a main concern in derailment would be the speed at which the train would bank. If the train is moving at a speed over the recommended speed at a certain area, it may overturn. An example would be the Santiago de Compostela derailment in Spain in 2013. Measures that are taking is that every morning, the train operators allow a low speed train carrying no passengers to make a round trip to check for any problems that there may be in the tracks [1].

\section{Power}

Just like every other machine, the high speed trains also require power to function. There have been trains which ran on coal or steam-powered engines. But to sustain a high-speed train, we need to have electrical power transfer. This section will discuss the different ways of powering the high-speed trains.

\subsection{Inductive power transfer}

As we learnt from our previous discussion that Maglev is a train which functions on the principle of electromagnetism. Therefore, to transfer power IPT is used since it's the most convenient for maglev.

IPT is basically the way how to efficiently carry electrical energy without any wires connection from a primary to a secondary across a relatively large air gap. The shape of the primary coil on a monorail is an elongated loop that is loosely coupled to a pickup coil on a vehicle and may transfer $1-10 \mathrm{~kW}$ of power across a 4-10-mm gap. The performance of IPT can be determined from two observable parameters: the open circuit voltage which is

Voc $=$ JuMI1

The short circuit current which is

$\mathrm{Isc}=\mathrm{MI} 1 / \mathrm{L} 2$

For IPT power the basic equation is the multiplication of the open circuit voltage and the short circuit current which is constant, so all the pickups on the track getting that current from Voc,

$\mathrm{Su}=\mathrm{Voc} * \mathrm{Isc}=(\mathrm{JumMI})(\mathrm{MI} 1 / \mathrm{L} 2)$.

A practical IPT system consists of primary track that has an elongated loop of wire which may be series compensated in order to ensure that the inductance, which is the property of an electric conductor or circuit that causes an electromotive force to be generated by a change in the current flowing, is within the limits able to be driven by the power supply. [4]

\subsubsection{Development of Monorail}

The pickup is placed on a moving unit, called sometimes bogie, the output power from that pickup is transformed into a useful power to make one motor or more that can move the bogie along the primary track. To ensure that the track with long lengths can be driven and to avoid any increment in cost, the track material should have no magnetic properties to increase the efficiency of the power transfer. However, each coupled pickup should use the magnetic material, for example, "ferrite" this will enhance the local coupling which will improve the power transfer. to enhance the coupling in a monorail system, it is suggested that the design of the magnetic material to extend partially within and around the track wires. For such monorail system, the industrial companies use some shapes, $\mathrm{E}$ or $\mathrm{U}$-shaped pickups and $\mathrm{S}$ which has higher power than $\mathrm{E}$ and $\mathrm{U} .[4]$ 


\subsection{Overhead wire contact system}

To ease the transfer of power for high-speed trains overhead contact systems were developed. They are basically long wires which run the length of the entire railway track and provide power to the train. They do that by establishing an electrical connection between the head of the train and the overhead wires.

The principle of power supply wiring is not that easy. The wire must be able to tolerate vagaries of the weather that sometimes be extremely cold and sometimes hot, withstand the wind and can take the current with several thousand amperes. The electric traction consists of some contact wires and it is supported at intervals by droppers from a simple or composite catenary wire [6]. Because of the curves in the track the contact wire should be pulled laterally and has to be held in tension horizontally and it will be in two tonnes per region. The wire length depends on the range of temp and it is between 1000,1500 $\mathrm{m}$ long. The dropper wire is attached by a clip which is fixed on the top side. At the end of the wire length, there are weights held to maintain the tension of the wire. And each length is extended over the next one cover it partly to make the pathway for the pan goes smoothly. [5]

\section{Flow Field Around The Train}

If we look at an average LRT train in Malaysia. We can observe that its front is almost like a bus's front. Compare that to an average Japanese bullet train, it has more of a streamlined shape. The purpose of this section is to put a comparative between these two cases and study why one is shaped the way it is. When the train say, is moving at speeds such as $140 \mathrm{~km} / \mathrm{h}$ or $39 \mathrm{~m} / \mathrm{s}$ the effect of rolling friction between tyre and the rail would be the major cause of resistance. LRT operates at similar speeds therefore it does not require its shape to be streamlined. But for a high-speed train which could reach up to speeds of $400 \mathrm{~km} / \mathrm{h}$ or $111 \mathrm{~m} / \mathrm{s}$ then there is more than just rolling friction involved, there will be another term adding to the resistance which is the aerodynamic drag. According to Schetz if a train were to travel at $250-300 \mathrm{~km} / \mathrm{h}$ only it would experience 75 $80 \%$ of its resistance from aerodynamic drag itself [7]. Therefore, to make high-speed train efficient it is mandatory on part of the engineers to make the shape of the train more streamlined. As we discussed in previous sections about the maglev, if a maglev train were to be used, there would be almost zero friction between the rail and the train itself. Therefore, the only thing that will contribute to the resistance will be the aerodynamic drag, which could be further divided into pressure drag and skin friction drag [7]. The skin friction usually occurs due to the boundary layer formation between the air and the surface of the train and is a direct result of shear stress. While pressure drag is caused due to the normal pressure acting on the surface of the train. So therefore an Aerodynamic drag is caused due to the pressure and shear stress. An aerodynamic shape will not only reduce the Aerodynamic drag but it will also improve the economic efficiency of the train.

\subsection{Flow field around the train in the open}

As discussed above, the two main sources of drag are the shear stress and the pressure. Let us for now neglect the effect of skin friction drag and assume the flow is in-viscid. If the shape of the train is streamlined all the way from the front till the end. The flow around the train would almost trace the entire shape of the train. But if there were suppose any discrepancies, the flow would stop at that point and an excessive pressure drag could form Fig. 2 [7].
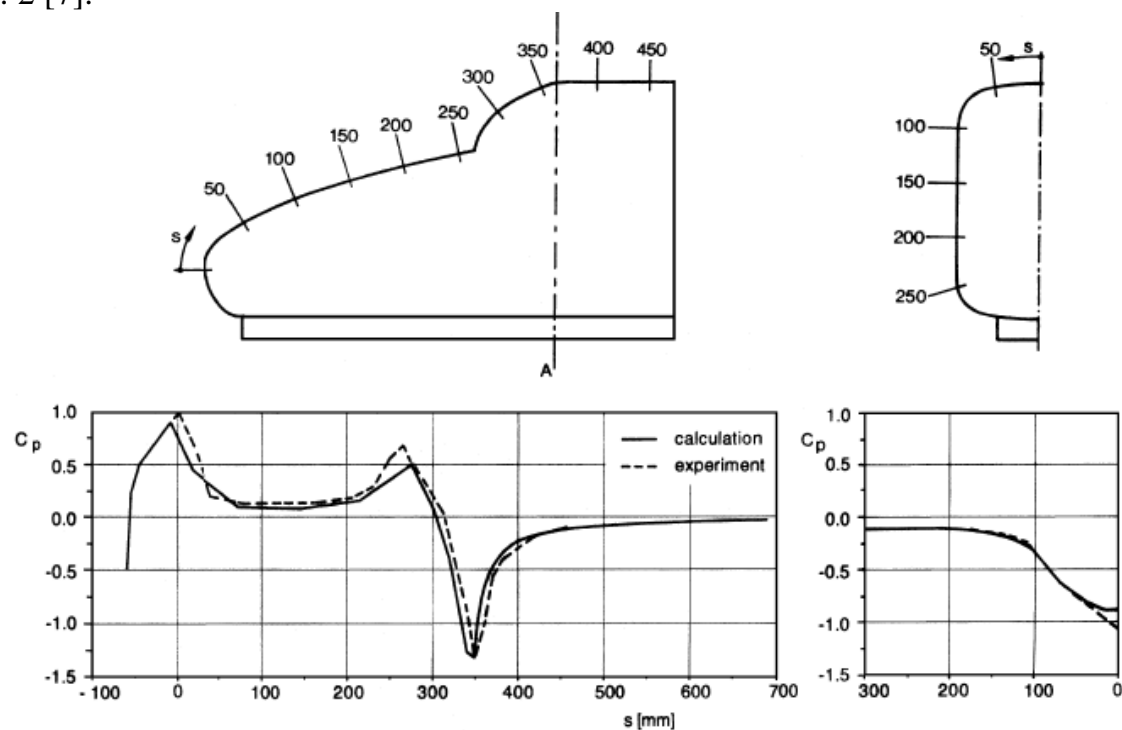

Fig.1. Measured and calculated pressure distributions on a train nose model (Machrodt et al 1980) 
In reality there is skin friction drag is present due to the wetted area which comes under the contact of the air, and we don't have any choice but to accept this drag, as well this might lead to formation of boundary layers and more drag. Suppose a wind of a certain velocity is moving in the opposite direction of a stationary train model. The $\mathrm{Cp}$ (Pressure coefficient) values are then calculated for this model and it is found that the Cp is highest at the nose due to the stagnation point from Fig.2 [7]. This implies that when the shape of the nose is blunt it increases the drag drastically as the body is not stream lined. Therefore, keeping the shape of the train as streamlined as far as possible will help to reduce the drag.

But to add to our worries there might be a crosswind acting on the train which could affect the yawing motion of the train. Moreover, there might me be the head or tail wind. Head will enhance the drag as it will work in the same direction as that of the drag force. It is assumed that the effects of crosswinds are stronger when a train is passing over a bridge [8]. The wheel and suspension method uses suspensions to balance derailment through banking, this could be used to counter crosswind effects as well. But for Maglev, the electromagnetic forces between the train and track are pretty strong to derail it. But these are all assumptions. The engineers must be aware of crosswinds and test their model before designing the train to avoid injuries.

\subsection{Flow field around the train passing through a tunnel}

There could be many reasons to have a train pass through a tunnel such as lack of flat areas, or if the train needed to pass through densely populated areas etc. The big problem with the flow characteristics of the train passing through a tunnel when arrives at the entrance and the exit. Suppose we have a reservoir full of water connected to a small pipe which drains it out. The water inside the reservoir is travelling at a speed and is now forced to go through a small area. As per the continuity equation the Velocity will increase drastically and therefore, according to the energy equation, the pressure will decrease drastically as well. Therefore, if a train from the open area enters into a narrow tunnel the air is pushed in at a high velocity and there is a sudden pressure drop within a very small distance. This leads to an increase in compressibility of the air, which leads to the formation of compression waves Fig.2 [8].

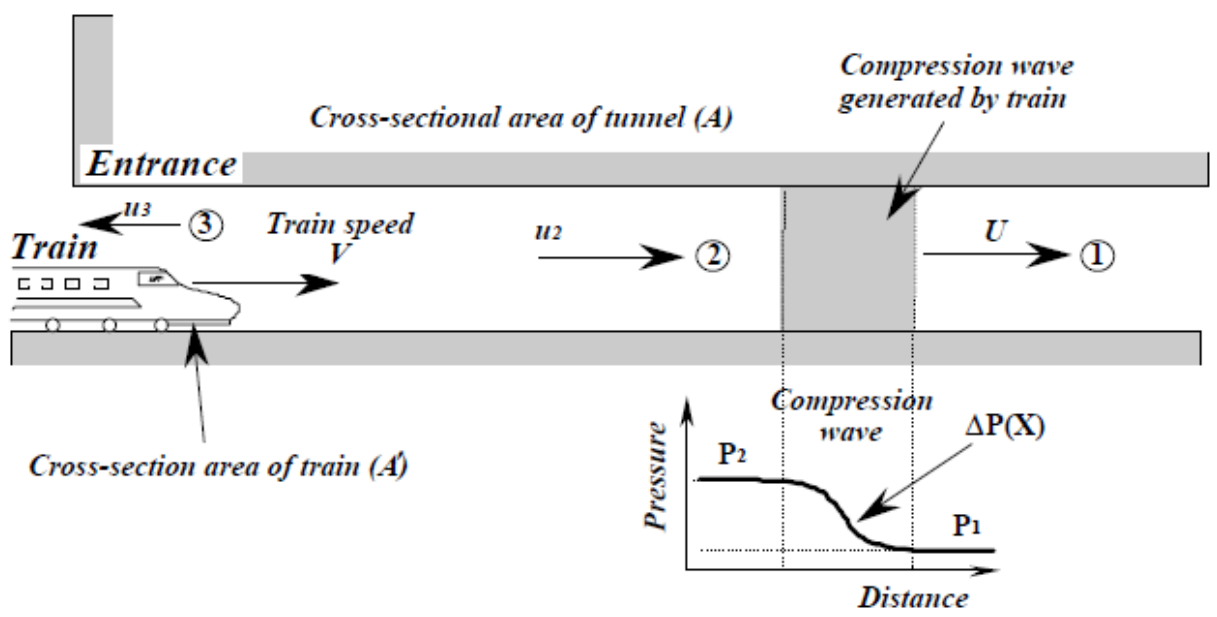

Fig.2. One-dimensional flow model of compression wave

If suppose the velocity of the air pushing through the tunnel reaches sonic velocity (i. e. Mach $M=1$ ) it will results in the formation of the Mach waves or if $M>1$ it could generate Shockwaves and sonic booms. There is a tunnel called the Euerwang tunnel in Germany which creates sonic booms when a train passes through it.

Therefore, to add to the pressure drag and skin friction drag we now have another component of the drag is the wave drag, which is caused by a sudden change in pressure through tunnel entrances. But to add to our worries, at the exit of the tunnel an impulse wave is generated [8]. This impulse wave is reflected back into the tunnel and it adds to the wave drag acting on the train. The sudden drop in pressure passing through the tunnel is not just an aerodynamic drag problem, it has direct effects on the structure of the train and also the people inside. To avoid this, maybe the trains could go slower when passing through tunnels. Or maybe the size of tunnels could be very large, or the structure used to make the train made in a way so that it could withstand the pressure drop, and have no effect on the people inside.

The main objective is to reduce cost, provide safety and comfort for the passengers and if all are achieved then it becomes an efficient model. Anyway the dream to achieve fast speeds for trains will always be something that people will strive for. And without the consideration of Aerodynamics on the train, the mission will never be achieved. 


\section{Economical Efficiency Of The High Speed Train}

The High speed train is so useful for people because that can save money, time and energy. High speed train is so fast and can cover long distances in a short time. HST is useful in term of weathers and crowding because it can operate in all conditions and without delaying in time especially in rush hours. HST has huge capacity and can transport with comfort. HST connect cities with each other's. HST bring labors to the city from one place to other. HST has a lot of economic impact like: creating jobs, increasing economic activities, reduce congestion, reduce the dependence on oil, and expand travel choices. [9]

\subsection{Creating new jobs:}

Building high speed train creates thousands of jobs. Statistically every 1 billion US dollar invested in HST creates 24000 jobs. Some of these jobs are skilled jobs which can improve the local rail industries. A lot of jobs are likely to be created because of the development of economic activities due to the HST.

\subsection{Increasing economic activities:}

By investing 1US dollar that will create 4 dollars in economic benefits. The HST services will connect the country economically and help it to connected, productive and internationally competitive.

\subsection{Reduce congestion:}

In some countries the cost of congestion is 140 million US dollars in lost of time and productivities. In the future the populations will increase and these people cannot prosper due to congestion in the roads and governments can satisfies the high demands of building new high ways and airports.

\subsection{Reduces the dependence on oil:}

By using high speed train that will reduce the oil spending and save a lot of money for the government because HST is efficient and consumes less oil by eight times as compared from plains and fourth times as compared to automobiles and that will lead to decrease in the emission of $\mathrm{CO} 2$ and improve air quality.

\subsection{Expands Travel Choices and Improves Mobility:}

High speed train can transport people from one place to another faster than airplane. The HST will create an integration among all transportation methods and will let work better. It will be another option for the people for transport.

\section{Conclusion}

In the end, because of the speed and perfect safety of the passengers, high speed train has become very popular in this world. Most of the countries nowadays are trying to develop this technology through developing the sectors [tracks, power generation, and aerodynamics] mentioned above.

Interesting study that can be done based on the review

A concept has been proposed by the CEO of SpaceX/Tesla, called "Hyperloop", whereby a train will travel through a vacuum space. In this concept the vacuum space is called the track of the train. So, the speed of the train estimated to $760 \mathrm{mi} / \mathrm{h}$ or $1220 \mathrm{~km} / \mathrm{h}$ (Mach number 1 approximately [11]

In many developed countries this project has started working in full pace. It's proclaimed by the company that by the end of summer 2017 the necessary information will be gathered completely to make the pod [body of the train]. [12]

A ground vehicle which is moving at a speed nearly Mach number 1 is anecdotal. If it [Hyperloop] manages to succeed, then the fairy tales wouldn't be myths anymore. People will be living in a world which no one could think of. Ergo, it is an obligation to the engineers to push "high speed train technology" further towards its development to make the ground journey more enjoyable and reliable in this world.

\section{References}

[1]. Guang Yang and Zhenmin Tang, The analysis of high-speed wheel-rail train and high-speed maglev train safety systems, Proceedings of ICSSSM '05. 2005 International Conference on Services Systems and Services Management, 2005., 2005, p. 1403-1407 Vol. 2.

[2]. K. Bonsor, How Maglev Trains Work,. [Online]. Available: http://science.howstuffworks.com/transport/enginesequipment/maglev-train1.htm K. Elissa, "Title of paper if known," unpublished. 13 October 2000.

[3]. J. McCurry, Japan's maglev train breaks world speed record with $600 \mathrm{~km} / \mathrm{h}$ test run, [Online]. Available: https://www.theguardian.com/world/2015/apr/21/japans-maglev-train-notches-up-new-world-speed-record-in-testrun. 21 April 2015.

[4]. R. G. Sell, G. E. Prince, and D. Twine, an Experimental Study of the Overhead Contact, Proc. Inst. Mech. Eng., vol. 179, no. 1, pp. 765-781, 1964. 
[5]. G. a. Covic and J. T. Boys, Inductive Power Transfer, Proc. IEEE, vol. 101, no. 6, pp. 1276-1289, 2013.

[6]. Unknown, "Electric Traction Power supplies," Railway Technical webpages. [Online]. Available: http://www.railway-technical.com/etracp.shtml\#Overhead-Line-Catenary

[7]. J. A. Schetz, aerodynamics of high -speed trains, no. Muhlenberg 1978, pp. 371-414, 2001.

[8]. R. S. Raghunathan, H. Kim, and T. Setoguchi, Aerodynamics of high-speed railway train, vol. 38. 2002.

[9]. Midwest High Speed Rail Association, The Economic Impacts of High Speed Rail : Transforming the Midwest.

[10]. [1] UIC, High Speed - International Union of Railways (UIC),. [Online]. Available: http://www.uic.org/highspeed\#General-definitions-of-highspeed. 2015

[11]. Hyperloop | Wikipedia. [Online]. Available: https://en.wikipedia.org/wiki/Hyperloop.

[12]. [2]Hyperloop | SpaceX. [Online]. Available: http://www.spacex.com/hyperloop. 